\title{
Association of phthalate exposure and airway dysfunction, with mediation by serum periostin
}

\author{
Heysung Baek ${ }^{1}$, Ha Young Won ${ }^{2}$, Ju Hee Kim ${ }^{3}$, Eun Kyo Ha ${ }^{4}$, Hye Mi Jee ${ }^{4}$, Youn Ho \\ $\mathrm{Shin}^{5}$, Mi Ae Kim ${ }^{6}$, and Man Yong $\mathrm{Han}^{4}$ \\ ${ }^{1}$ Hallym University Kangdong Sacred Heart Hospital \\ ${ }^{2}$ Clinical Research Institute, Kangdong Sacred Heart Hospital, Hallym University College \\ of Medicine \\ ${ }^{3}$ CHA Bundang Medical Center \\ ${ }^{4} \mathrm{CHA}$ University School of Medicine \\ ${ }^{5}$ CHA Gangnam Medical Center, CHA University School of Medicine \\ ${ }^{6}$, CHA Medical Center, CHA University School of Medicine
}

November 16, 2020

\begin{abstract}
Background: Phthalates can cause respiratory and immunological disorders. However, little is known about the role of serum periostin and YKL-40 levels in mediating the effects of phthalates. We investigated the mediating role of these biomarkers in the relationship between phthalates and airway dysfunction. Methods: A total of 487 children (aged 10 to 12 years-old) were examined. Four high-molecular-weight phthalate (HMWP) [ $\Sigma 4$ HMWP] metabolites and 3 low-molecular-weight phthalate (LMWP) [ S3LMWP] metabolites in urine samples were measured. Serum periostin and YKL-40 levels were measured. Airway function was measured using impulse oscillometry. A mediation model was used to quantify the mediating effects of periostin and YKL-40 on airway dysfunction. Results: After adjustment for height, gender, BMI z-score, aeroallergen sensitization, secondary smoking, and vitamin D level, the level of urinary $\Sigma$ 3LMWP metabolites was significantly associated with respiratory system resistance at $5 \mathrm{~Hz}$ (Rrs5; adjusted $\beta: 0.020,95 \% \mathrm{CI}: 0.005$ to $0.034 ; \mathrm{P}=.010)$. The levels of urinary $\Sigma 4 \mathrm{HMWP}$ and $\Sigma 3 \mathrm{LMWP}$ metabolites were significantly associated with periostin level, but not with YKL-40 level. In addition, the periostin level was associated with Rrs5 (adjusted $\beta$ : 0.048, 95\% CI: 0.015 to 0.081; P = .005) and Rrs20-5 (adjusted $\beta$ : 0.040, 95\% CI: 0.011 to $0.069 ; \mathrm{P}=.007$ ). Serum periostin level had a significant effect in mediating the relationship between $\Sigma 3 \mathrm{LMWP}$ and Rrs5 $(13.9 \%, 95 \%$ CI: 10.7 to $77.0 ; \mathrm{P}<.001)$. Conclusion: Exposure to LMWPs was significantly associated with airway dysfunction, and this effect was partially attributable to increased serum periostin level.
\end{abstract}

Association of phthalate expxosure and airway dysfunction, with mediation by serum periostin a running title: Phthalate, airway dysfunction and periostin

Hey Sung Baek ${ }^{1}$, Ha Young Won ${ }^{2}$, Ju Hee Kim³ ${ }^{3}$ Eun Kyo Ha4, Hye Mi Jee ${ }^{3}$, Youn Ho Shin ${ }^{5}$, Mi-Ae Kim ${ }^{6}$, Man Yong Han3

Author affiliations:

1. Department of Pediatrics, Kandong Sacred Heart Hospital, Hallym University College of Medicine, Seoul, Korea

2. Clinical Research Institute, Kangdong Sacred Heart Hospital, Hallym University College of Medicine, Seoul, Korea 
3. Departments of Pediatrics, CHA Bundang Medical Center, CHA University School of Medicine, Seongnam, Korea

4. Department of Pediatrics, Kangnam Sacred Heart Hospital, Hallym University Medical Center, Seoul, Korea

5. Department of Pediatrics, CHA Gangnam Medical Center, CHA University School of Medicine, Seoul, Korea

6. Department of Internal Medicine, CHA Bundang Medical Center, CHA University School of Medicine, Seongnam, Korea

*Corresponding author

Professor Man Yong Han, MD

Department of Pediatrics, CHA University School of Medicine

59, Yatap-ro, Bundang-gu, Seongnam-si, Gyeonggi-do, 13496, Republic of Korea

Phone: +82-31-780-6262; Fax: +82-31-780-5239

\section{The contribution of each author}

Heysung Baek, MD, PhD: conception and design of the study, analysis and interpretation of the data paviola7@gmail.com

Ha Young Won, MS: collection of the data and interpretation of the data

why3719@kdh.or.kr

Ju Hee Kim, MD: collection of the data and interpretation of the data

2004052@gmail.com

Eun Kyo Ha, MD: collection of the data and interpretation of the data

dmsry1@gmail.com

Hye Mi Jee MD, PhD: collection of the data and interpretation of the data

hyemijee@gmail.com

Youn Ho Sheen, MD, PhD: analysis and interpretation of the data

epirubicin13@gmail.com

Mi-Ae Kim, MD, PhD: analysis and interpretation of the data

makim7851@gmail.com

ManYong Han, MD, PhD: conception and design of the study, collection of the data and analysis and interpretation of the data

drmesh@gmail.com

Total Word Count: 2,492

Number of tables and figures; 6

Association of phthalate exposure and airway dysfunction, with mediation by serum periostin Conflicts of interest

All authors declare no conflict of interest. 


\section{Funding}

This research was supported by the Hallym University Kangdong Sacred Heart hospital Research Fund (grant number: 2018-05) and by a grant from the Seongnam Atopy Project of the Seongnam City Government, Republic of Korea.

\section{ABSTRACT}

Background : Phthalates can cause respiratory and immunological disorders. However, little is known about the role of serum periostin and YKL-40 levels in mediating the effects of phthalates. We investigated the mediating role of these biomarkers in the relationship between phthalates and airway dysfunction.

Methods: A total of 487 children (aged 10 to 12 years-old) were examined. Four high-molecular-weight

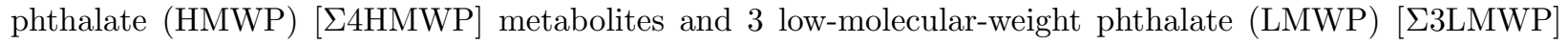
metabolites in urine samples were measured. Serum periostin and YKL-40 levels were measured. Airway function was measured using impulse oscillometry. A mediation model was used to quantify the mediating effects of periostin and YKL-40 on airway dysfunction.

Results: After adjustment for height, gender, BMI z-score, aeroallergen sensitization, secondary smoking, and vitamin D level, the level of urinary $\Sigma$ 3LMWP metabolites was significantly associated with respiratory system resistance at $5 \mathrm{~Hz}$ (Rrs5; adjusted $\beta: 0.020,95 \% \mathrm{CI}: 0.005$ to $0.034 ; \mathrm{P}=.010$ ). The levels of urinary इ4HMWP and $\Sigma$ 3LMWP metabolites were significantly associated with periostin level, but not with YKL-40 level. In addition, the periostin level was associated with Rrs5 (adjusted $\beta$ : 0.048, 95\% CI: 0.015 to 0.081; $\mathrm{P}=.005$ ) and Rrs20-5 (adjusted $\beta: 0.040,95 \% \mathrm{CI}: 0.011$ to $0.069 ; \mathrm{P}=.007$ ). Serum periostin level had a significant effect in mediating the relationship between $\Sigma$ LMWP and Rrs5 (13.9\%, 95\% CI: 10.7 to 77.0; P $<.001)$.

Conclusion: Exposure to LMWPs was significantly associated with airway dysfunction, and this effect was partially attributable to increased serum periostin level.

\section{Key words}

1. Phthalate

2. perisotin

3. chitinase-like proteins (YKL-40)

4. airway dysfunction

\section{Key Messages}

Phthalates have known adverse effects on the respiratory and immunological systems. However, the mechanisms by which they promote asthma, impaired lung function, and airway inflammation are unknown because few studies have thoroughly examined this topic. We found that exposure to low-molecular-weight phthalates was significantly associated with airway dysfunction, and this effect is partially attributable to increased serum periostin level. Our results suggest that periostin might stimulate Th2 cell-mediated inflammation and thereby cause pulmonary dysfunction in children exposed to phthalates.

\section{INTRODUCTION}

Previous studies reported that exposures to environmental pollutants are responsible for the increasing prevalence of allergic diseases. ${ }^{1,2}$ Here, we focused on phthalates, a group of chemicals commonly used as plasticizers that commonly have higher concentrations in children than adults. ${ }^{3}$ Phthalates can have adverse effects on the respiratory and immunological systems. Epidemiological studies reported positive associations between indicators of phthalate exposure and risk of asthma, and allergic diseases. ${ }^{4,5}$ Other studies reported that phthalates also adversely affect pulmonary functions. ${ }^{6,7}$ Experimental studies demonstrated that exposure to phthalates increased the levels of T helper 2 (Th2) cells and cytokines, and also increased 
airway inflammation. ${ }^{8,9}$ Several clinical studies found an association between phthalate exposure and fractional exhaled nitric oxide (FeNO) ${ }^{5,8}$ The immunological mechanisms by which phthalate exposure leads to asthma and disruptions of lung function and airway inflammation are unknown. In addition, few studies have examined the association of phthalate exposure with allergic inflammation and lung function.

Recent studies identified periostin and chitinase-like proteins as biomarkers of asthma. Periostin promotes chronic allergic inflammation in response to Th2-associated cytokines by inducing proinflammatory cytokines. ${ }^{10}$ Chitinase-3-like protein 1 , also known as YKL-40, is a glycoprotein secreted by various cell types, including macrophages, neutrophils, and airway epithelial cells. ${ }^{11}$ However, little is known about the levels or function of periostin and YKL-40 following exposure to environmental pollutants or other chemicals. We hypothesized that phthalate exposure may alter the serum levels of periostin and YKL-40.

Our primary objective was to determine the associations between phthalate exposure and pulmonary functions in a population-based sample of randomly selected sixth-grade students from 11 elementary schools in Korea. Our secondary objective was to examine the potential role of periostin and YKL-40 in mediating the relationship between phthalate exposure and airway dysfunction.

\section{METHODS}

\section{Subjects and Protocol}

A total of 620 fifth- and sixth-grade elementary school students (10-12 years old) who participated in the Seongnam Atopy Project (SAP) 2017 cohort were enrolled. This study was sponsored by the Seongnam City Government for the prevention and education of allergic diseases in Korean children and was conducted between January 2017 and October 2017. ${ }^{12}$

Demographic data were collected, and questionnaires completed by the parents were used to record symptoms of the children during the previous 12 months (wheezing, nasal symptoms, and eczema), based on the International Study of Asthma and Allergies in Childhood (ISAAC) questionnaire. ${ }^{13}$. Urine samples were collected in sterile cups and stored at $-70^{\circ} \mathrm{C}$ for up to 3 months before analysis. Blood samples were stored at -70degC until determination of the levels of serum periostin, serum YKL-40, and total and allergen-specific immunoglobulin (Ig) E. FeNO levels were measured by a physician and impulse oscillometry (IOS) was performed by a well-trained technician. The study protocol was approved by the appropriate Institutional Review Board of CHA University (2017-04-049), and written informed consent documents were obtained from all parents or guardians of participating children.

\section{Measurement of phthalate metabolites}

Phthalate metabolite concentrations were determined by gas chromatography/tandem mass spectroscopy. ${ }^{14}$ Reported phthalate concentrations were expressed relative to urinary creatinine $(\mu \mathrm{g} / \mathrm{g} \mathrm{UCr}$ ) to control for urine dilution. A total of 455 urine samples were analyzed for the following 7 phthalate metabolites: mono(iso-butyl) phthalate (MiBP), mono-isononyl phthalate (MNP), mono-benzyl phthalate (MBzP), mono-(3carboxypropyl) phthalate (MCPP), mono-(2-ethyl-5-hydroxyhexyl) phthalate (MEHHP), mono-(2-ethyl-5oxohexyl) phthalate (MEOHP), and mono-(2-ethyl-5-carboxypentyl) phthalate (MECPP). (Appendix S1: Fig. E1). Phthalate metabolites were grouped based on molecular weight and reported as the sum of 4 major high-molecular weight phthalate $\left(\Sigma_{4} \mathrm{HMWP}\right)$ metabolites (MEHP, MEOHP, MECPP, and MCPP), or the sum of the 3 major low-molecular weight phthalate ( $\Sigma_{3}$ LMWP) metabolites (MiBP, MNP, and MBzP). They were further divided into quartiles according to concentration (lowest to highest,Q1 to Q4). Previous research indicated these two groups of metabolites have different physicochemical properties. ${ }^{14,15}$

\section{Lung function measurements and FeNO}

IOS was performed in accordance with established guidelines. ${ }^{16}$ The difference of the respiratory system resistance (Rrs) at $5 \mathrm{~Hz}$ and $20 \mathrm{~Hz}$ (Rrs5-20) has a high sensitivity for detecting small airway dysfunction. ${ }^{17}$ Airway resistance was also measured at $1,2,3,5,10,15$, and $20 \mathrm{~Hz}$ for calculation of area of reactance (AX) as 
a function of frequency. The signals were analyzed for $30 \mathrm{~s}$ at each frequency. Oscillometric tests were performed using a Jaeger MasterScreen device (Jaeger Co., Wurzburg, Germany).

The FeNO concentration in exhaled breath in parts per billion (ppb) was measured using a portable nitric oxide analyzer (NIOX MINOß); Aerocrine, Solna, Sweden) according to the American Thoracic Society (ATS) guidelines. ${ }^{18}$

\section{Measurement of serum biomarkers}

Serum total and specific IgE antibodies for common aeroallergens (Dermatophagoides farinae, cat dander, dog dander, birch,Alternaria alternata, and Humulus japonicus ) were measured using the ImmunoCAP system (Phadia, Uppsala, Sweden). Atopy was defined by positive specific IgE antibodies to at least one common inhaled allergen. Serum periostin was determined using the Human Periostin/OSF-2 DuoSet ELISA Kit (catalog number DY3548B; R\&D Systems, Inc., Minneapolis, MN). Serum YKL-40 was determined using the Human Chitinase 3-like 1 Quantikine ELISA Kit (catalog number DC3L10; R\&D Systems, Inc., Minneapolis, MN).

\section{Statistical analysis}

The data were analyzed using SPSS version 21.0 (SPSS, Chicago, IL) and R software version 3.6.3. Continuous data are expressed as means with standard deviations or as medians with the interquartile ranges, depending on the data distribution. The relationships of the concentrations of different of urinary phthalates with serum periostin level, Rrs5, and Rrs5-20 were analyzed using linear regression with adjustment for height, gender, BMI $z$-score, aeroallergen sensitization, secondary smoking, and vitamin D level. The estimates were regression slopes for phthalate concentration vs. periostin level and Rrs5. Beta $(\beta)$ and a $95 \%$ confidence interval (CI) were obtained from a generalized linear regression model with the gamma function. The $\mathrm{R}$ package, "Mediation" ${ }^{19}$ was used to quantitatively estimate the mediating effect of periostin level in the association of phthalate concentration with Rrs5 and Rrs5-20. This package estimates confidence intervals using bootstrapping with 1000 resamples. A two-sided $P$ value of .05 or less indicated statistical significance.

\section{RESULTS}

\section{Characteristics of study subjects}

We recruited 487 fifth- and sixth-grade students for this study (Table 1). The average age was 11.01 years (95\% CI: 10.9 to 11.1 ) and the average BMI $z$ - score was -0.02 (95\% CI: -0.11 to 0.07 ). Fifty-six children $(11.7 \%)$ had wheezing at some time, $28(5.8 \%)$ had asthma, and $25(10.9 \%)$ were born premature and/or had low birth weight. A total of $61.4 \%$ of the children had atopic sensitization. The median level of serum periostin was $35.7(\mathrm{ng} / \mathrm{mL})$ and the median level of YKL-40 was $21.47(\mathrm{ng} / \mathrm{mL})$. Table 1 shows the IOS parameters.

\section{Association of phthalate concentration with lung function and FeNO level}

Analysis of the association of the quartiles of phthalate metabolites with Rrs5 (Table 2, Figure 1) indicated the quartiles of urinary $\Sigma_{4}$ HMWP metabolites were associated with greater Rrs5 (Crude $\beta$ : 0.028; 95\% CI: 0.011 to $0.046 ; P=.001$ ), but these associations were not significant after adjusting for height, gender, BMI $z$-score, aeroallergen sensitization, secondary smoking, and vitamin D level. However, after adjusting for these same confounders, $\Sigma_{4}$ HMWP was significantly associated with Rrs1 (Q1/Q4, adjusted $\beta$ : 0.047, 95\% CI: 0.009 to $0.084, P=.015$ ), Rrs2 (Q1/Q4, adjusted $\beta$ : 0.046, 95\% CI: 0.007 to $0.084, P=.021$ ), and Rrs3 (Q1/Q4, adjusted $\beta$ : $0.057,95 \%$ CI: 0.015 to $0.099, P=0.008$ ) (Figure 1A).

Children with higher quartiles of $\Sigma_{3}$ LMWP metabolites (Table 2, Fig. 1) also had significantly greater Rrs5 (Crude $\beta$ : $0.028,95 \%$ CI: 0.011 to $0.045 ; P=.001$ ) and this relationship remained significant after adjustment for confounding (adjusted $\beta: 0.020,95 \%$ CI: 0.005 to $0.034 ; P=.010$ ). In addition, after adjusting for confounding, quartiles of $\Sigma_{3}$ LMWP was also significantly associated with Rrs1 (Q1/Q4, adjusted $\beta$ : 0.046, 95\% CI: 0.008 to $0.083, P=.018$ ), Rrs2 (Q1/Q4, adjusted $\beta: 0.051,95 \%$ CI: 0.012 to $0.089, P=.010$ ), Rrs3 
(Q1/Q4, adjusted $\beta$ : 0.057, 95\% CI: 0.015 to 0.099, $P=.008$ ), Rrs10 (Q1/Q4, adjusted $\beta: 0.055,95 \%$ CI: 0.010 to $0.099, P=.016$ ), and Rrs15 (Q1/Q4, adjusted $\beta$ : $0.055,95 \%$ CI: 0.001 to $0.109, P=.044$ ).

After adjustment for confounding, there was a significant association in the quartiles of urinary $\Sigma_{4} \mathrm{HMWP}$ metabolites with FeNO (adjusted $\beta$ : 0.053, 95\% CI: 0.007 to 0.099; $P=0.024$ ), but no significant association in the quartiles of urinary $\Sigma_{3}$ LMWP metabolites with FeNO (Table 2).

\section{Associations of phthalate concentrations with serum periostin level, YKL-40 level, and lung function}

Analysis of the relationships of urinary phthalate metabolites with serum periostin level and serum YKL-40 level indicated significant associations in the quartiles of urinary $\Sigma_{4}$ HMWP and $\Sigma_{3}$ LMWP metabolites with periostin (Table 3). After adjustment using a generalized linear regression model with the logit function, these relationships remained significant. After adjustment, the level of urinary $\Sigma_{4}$ HMWP metabolites was also significantly associated with YKL-40 (adjusted $\beta$ : 0.882 , 95\% CI: 0.687 to $0.983 ; P=.032$ ), but level of urinary $\Sigma_{3}$ LMWP metabolites was not significantly associated with YKL-40 level.

Analysis of the relationships of serum periostin and serum YKL-40 levels with pulmonary function indicated periostin level was significantly associated with Rrs5 (adjusted $\beta: 0.048,95 \%$ CI: 0.015 to $0.081 ; P=.005$ ), but not with FeNO (Table 4). There was also a significant association between periostin level and Rrs520 (adjusted $\beta$ : $0.040,95 \%$ CI: 0.011 to $0.069 ; P=.007$ ). The serum YKL-40 level was not significantly associated with Rrs5 or Rrs5-20.

\section{Mediating effect of periostin on lung function}

We performed an in-depth analysis of the potential role of periostin in mediating the association between the level of urinary phthalate metabolites and Rrs5 (Fig. 2). The results indicated that a higher $\Sigma_{3} \mathrm{LMWP}$ level had a significant and direct association with a higher Rrs5 ( $\beta$ : $0.084,95 \%$ CI: 0.005 to $0.14, P=0.04$ ), and that some of the effect of $\Sigma_{3}$ LMWP was mediated by an increased periostin level $(\beta: 0.013,95 \%$ CI: 0.002 to $0.030, P<0.001)$. Periostin mediates the relationship between $\Sigma_{3}$ LMWP level and Rrs5 $(13.9 \%$ mediation, $95 \%$ CI: 10.7 to $77.0 ; P<.001)$.

\section{DISCUSSION}

The role of environmental phthalate exposure on allergic airway diseases has been a topic of great interest. However, very few studies have examined the association of phthalate exposure with allergic inflammation and lung function. Our measurements of IOS in a population-based sample of children showed that an increased level of urinary phthalate metabolites was significantly associated with airway dysfunction, and that this association was partially attributable to an increased serum periostin level. Moreover, the associations we identified persisted after adjusting for multiple covariates (height, gender, BMI $z$-score, aeroallergen sensitization, secondary smoking, and vitamin D level).

Phthalate exposure may occur from ingestion, inhalation, dermal absorption, and parenteral administration. ${ }^{20,21}$ LMWPs are used in a variety of personal-hygiene and cosmetic products, such as nail polish and fragrances, as scent stabilizers. ${ }^{22}$ HMWPs are used in plastic tubing, food packaging, containers, vinyl toys, vinyl floor coverings, and building products. ${ }^{21,22}$ Koch et al. ${ }^{14}$ showed that exposure to HMWPs was mostly due to dietary intake, and that exposure to LMWPs was mainly from non-dietary exposures, such as from personal care products, dust, and indoor air. ${ }^{14}$ In the present study, we showed that children with higher urinary levels of LMWPs had significantly greater airway resistance after adjusting for confounding variables.

Experimental studies demonstrated that exposure to phthalates increases the levels of Th2 cells and multiple cytokines, and thereby enhances airway inflammation. ${ }^{8,9}$ Clinical studies found an association between phthalate exposure and FeNO. ${ }^{5,8}$ Serum periostin is a biomarker of type- 2 inflammation in asthma. ${ }^{23}$ The exact function of YKL-40 remains unclear, but it consistently correlates with airway obstruction in studies of patients with asthma, ${ }^{24-26}$ and with measures of airway remodeling, such as bronchial wall thickness and 
subepithelial fibrosis. ${ }^{24,25}$ Little is known about the function of periostin and YKL-40 in patients with allergic inflammation related to environmental pollutants. We initially hypothesized that there may be some differences in serum levels of periostin and YKL-40 following phthalate exposure because type-2 and nontype-2-induced airway inflammation are involved in phthalate-related airway inflammation. We therefore evaluated the relationships of serum periostin and YKL-40 levels in children with phthalate exposure, and investigated their relevance to clinical characteristics and other type-2 biomarkers, including blood eosinophil counts, serum total IgE, and FeNO. We found that FeNO level was significantly associated with the quartiles of urinary $\Sigma_{4}$ HMWP metabolites, but not quartiles of urinary $\Sigma_{3}$ LMWP metabolites. Our multivariate linear regression analysis indicated that urinary $\Sigma_{4}$ HMWP and $\Sigma_{3}$ LMWP metabolites were both significantly associated with serum periostin level. These findings are clinically significant because they demonstrate an association between phthalate exposures with serum periostin, an established marker of Th2 inflammation. However, we found no significant associations in the levels of urinary $\Sigma_{4}$ HMWP and $\Sigma_{3}$ LMWP metabolites with serum YKL-40 level. These results suggest that serum periostin may be used as a biomarker for type-2 inflammation in children following phthalate exposure, but serum YKL-40 has less value for this assessment.

We found that serum periostin level was significantly associated with Rrs5 and Rrs20-5. This outcome is similar to that of a recent study which reported the relationship between periostin level and pulmonary function in asthma patients. This previous study found that patients with high periostin levels had lower $\mathrm{FEV}_{1} / \mathrm{FVC}$ values. ${ }^{27}$ Although there are reports of associations between pulmonary function and periostin level, there are only limited data on the relationships of periostin with small airway function. We therefore used an objective method - IOS — to evaluate small airway dysfunction our patients.

We found that periostin had a significant effect in mediating the relationship between urinary LMWP metabolites and airway resistance. To quantify this mediating effect, we performed a model-based mediation analysis by using the mediation package in R software. ${ }^{19}$ The algorithm uses a quasi-Bayesian Monte Carlo method to estimate the presence of mediation (average causal mediation effect/indirect effect) and the proportion of the link between phthalate exposure and airway dysfunction that is mediated by periostin. ${ }^{19}$

There are several limitations to the present study. First, because this was a cross-sectional study, we did not obtain any direct evidence for cause-and-effect relationships. Second, use of periostin as a dependable biomarker in growing children may be questionable because it is an extracellular matrix protein that is secreted by osteoblasts. However, the levels in our study subjects (10-12 years-old) were not higher than published values for adults ${ }^{28}$ and were not significantly associated with age (data not shown).

To the best of our knowledge, this is the first large-sample study of urban children to comprehensively investigate the role of periostin in mediating the relationship between phthalate exposure and airway dysfunction. Previous studies have investigated the association of phthalate exposure with other inflammation markers, but no previous studies investigated the role of periostin and YKL-40 on airway dysfunction in children exposed to phthalates. Another merit of this study is that we assessed small airway function using IOS.

In conclusion, we found that exposure to low-molecular-weight phthalates was significantly associated with airway dysfunction, and this effect is partially attributable to increased serum periostin level. Periostin appears to function in the Th2 cell-mediated inflammation that causes pulmonary dysfunction in children exposed to phthalates, but further studies are required to clarify this relationship.

\section{Acknowledgments}

We are grateful to the children and families who participated in the study for their support and dedication. We thank the Department of Environment Policy of the Seongnam City Government for its assistance and cooperation.

\section{REFERENCES}

1. Winans B, Humble MC, Lawrence BP. Environmental toxicants and the developing immune system: a missing link in the global battle against infectious disease? Reprod Toxicol. 2011;31(3):327-336. 
2. Yang SI. Particulate matter and childhood allergic diseases.Korean J Pediatr. 2019;62(1):22-29.

3. Brock JW, Caudill SP, Silva MJ, Needham LL, Hilborn ED. Phthalate monoesters levels in the urine of young children. Bull Environ Contam Toxicol. 2002;68(3):309-314.

4. Jaakkola JJ, Knight TL. The role of exposure to phthalates from polyvinyl chloride products in the development of asthma and allergies: a systematic review and meta-analysis. Environ Health Perspect.2008;116(7):845-853.

5. Just AC, Whyatt RM, Miller RL, et al. Children's urinary phthalate metabolites and fractional exhaled nitric oxide in an urban cohort.Am J Respir Crit Care Med. 2012;186(9):830-837.

6. Cakmak S, Dales RE, Hebbern C, Saravanabhavan G. The association between urinary phthalates and lung function. J Occup Environ Med. 2014;56(4):376-381.

7. Kim MA, Yon DK, Jee HM, et al. Association of phthalates with nasal patency and small airway dysfunction in first-grade elementary school children. Allergy. 2020.

8. Jahreis S, Trump S, Bauer M, et al. Maternal phthalate exposure promotes allergic airway inflammation over 2 generations through epigenetic modifications. J Allergy Clin Immunol.2018;141(2):741-753.

9. Oie L, Hersoug LG, Madsen JO. Residential exposure to plasticizers and its possible role in the pathogenesis of asthma. Environ Health Perspect. 1997;105(9):972-978.

10. Masuoka M, Shiraishi H, Ohta S, et al. Periostin promotes chronic allergic inflammation in response to Th2 cytokines. J Clin Invest. 2012;122(7):2590-2600.

11. Tong X, Wang D, Liu S, et al. The YKL-40 protein is a potential biomarker for COPD: a meta-analysis and systematic review. Int $J$ Chron Obstruct Pulmon Dis. 2018;13:409-418.

12. Lee S, Koh HY, Yon DK, et al. Association of Sensitization to Different Aeroallergens With Airway Function and Nasal Patency in Urban Children. Allergy Asthma Immunol Res. 2019;11(4):572-582.

13. Lee SI, Shin MH, Lee HB, et al. Prevalences of symptoms of asthma and other allergic diseases in korean children: a nationwide questionnaire survey. J Korean Med Sci. 2001;16(2):155-164.

14. Koch HM, Lorber M, Christensen KL, Palmke C, Koslitz S, Bruning T. Identifying sources of phthalate exposure with human biomonitoring: results of a $48 \mathrm{~h}$ fasting study with urine collection and personal activity patterns. Int J Hyg Environ Health. 2013;216(6):672-681.

15. Gascon M, Casas M, Morales E, et al. Prenatal exposure to bisphenol A and phthalates and childhood respiratory tract infections and allergy.J Allergy Clin Immunol. 2015;135(2):370-378.

16. Beydon N, Davis SD, Lombardi E, et al. An official American Thoracic Society/European Respiratory Society statement: pulmonary function testing in preschool children. Am J Respir Crit Care Med.2007;175(12):1304-1345.

17. Boccaccino A, Peroni DG, Pietrobelli A, et al. Assessment of variable obstruction by forced expiratory volume in 1 second, forced oscillometry, and interrupter technique. Allergy Asthma Proc.2007;28(3):331-335.

18. Dweik RA, Boggs PB, Erzurum SC, et al. An official ATS clinical practice guideline: interpretation of exhaled nitric oxide levels (FENO) for clinical applications. Am J Respir Crit Care Med.2011;184(5):602-615.

19. Tingley D, Yamamoto T, Hirose K, Keele L, Imai K. mediation: R Package for Causal Mediation Analysis. J Stat Softw. 2014;59(5).

20. Shea KM, American Academy of Pediatrics Committee on Environmental H. Pediatric exposure and potential toxicity of phthalate plasticizers.Pediatrics. 2003;111(6 Pt 1):1467-1474.

21. Kueseng P, Thavarungkul P, Kanatharana P. Trace phthalate and adipate esters contaminated in packaged food. J Environ Sci Health B. 2007;42(5):569-576. 
22. In: Phthalates and Cumulative Risk Assessment: The Tasks Ahead. Washington (DC)2008.

23. Woodruff PG, Modrek B, Choy DF, et al. T-helper type 2-driven inflammation defines major subphenotypes of asthma. Am J Respir Crit Care Med. 2009;180(5):388-395.

24. Chupp GL, Lee CG, Jarjour N, et al. A chitinase-like protein in the lung and circulation of patients with severe asthma. N Engl J Med. 2007;357(20):2016-2027.

25. Konradsen JR, James A, Nordlund B, et al. The chitinase-like protein YKL-40: a possible biomarker of inflammation and airway remodeling in severe pediatric asthma. J Allergy Clin Immunol.2013;132(2):328-335 e325.

26. Tang H, Fang Z, Sun Y, et al. YKL-40 in asthmatic patients, and its correlations with exacerbation, eosinophils and immunoglobulin E.Eur Respir J. 2010;35(4):757-760.

27. Shirai T, Hirai K, Gon Y, et al. Combined Assessment of Serum Periostin and YKL-40 May Identify Asthma-COPD Overlap. J Allergy Clin Immunol Pract. 2019;7(1):134-145 e131.

28. Corren J, Lemanske RF, Hanania NA, et al. Lebrikizumab treatment in adults with asthma. $N$ Engl $J$ Med. 2011;365(12):1088-1098.

\section{Tables}

Table 1. Demographic and clinical characteristics of study subjects $(\mathrm{N}=487)$

\begin{tabular}{|c|c|c|}
\hline Variable & Value & Value \\
\hline & Mean & $95 \%$ CI \\
\hline Age, years & 11.0 & 10.9 to 11.1 \\
\hline BMI $z$-score & -0.02 & -0.11 to 0.07 \\
\hline Height, cm & $\begin{array}{l}149.4 \\
\mathrm{n}^{*}\end{array}$ & $\begin{array}{l}148.7 \text { to } 150.1 \\
\%\end{array}$ \\
\hline Wheezing (ever) & $56 / 479$ & 11.7 \\
\hline Asthma, physician diagnosis & $28 / 486$ & 5.8 \\
\hline Passive smoking & $211 / 483$ & 43.6 \\
\hline Atopic sensitization $^{+}$ & $\begin{array}{l}289 / 479 \\
\text { Median }\end{array}$ & $\begin{array}{l}61.4 \\
\text { IQR }\end{array}$ \\
\hline Blood periostin,ng/mL & 35.7 & 27.3 to 43.6 \\
\hline Blood YKL-40, ng/mL & 21.4 & 17.4 to 27,4 \\
\hline Total IgE, IU/mL $\mathrm{mL}^{3}$ & 103.0 & 40.9 to 276.0 \\
\hline Blood eosinophil, $10^{9}$ cells $/ \mathrm{L}^{4}$ & 170.2 & 107.5 to 277.3 \\
\hline Vitamin $\mathrm{D}, \mathrm{ng} / \mathrm{ml}^{5}$ & 21.0 & 17.1 to 25.4 \\
\hline FeNO, $\mathrm{ppb}^{6}$ & $\begin{array}{l}15.0 \\
\text { Median }\end{array}$ & $\begin{array}{l}11.0 \text { to } 22.0 \\
\text { IQR }\end{array}$ \\
\hline $\operatorname{Rrs} 5, \mathrm{hPa} / \mathrm{L} / \mathrm{s}$ & 4.92 & 4.32 to 5.60 \\
\hline Rrs5-20, hPa/L/s & 1.74 & 1.33 to 2.29 \\
\hline $\mathrm{AX}, \mathrm{hPa} / \mathrm{L} / \mathrm{sc}$ & 10.90 & 7.87 to 14.93 \\
\hline
\end{tabular}

IQR, interquartile range; BMI, body mass index; IgE: immunoglobulin E; FeNO, fractional nitric oxide; Rrs5, resistance of respiratory system at $5 \mathrm{~Hz}$; Rrs5-20, the difference of the Rrs at $5 \mathrm{~Hz}$ and $20 \mathrm{~Hz}$; AX, reactance area

${ }^{*}$ Number of exposed or cases.

${ }^{+}$Inhalant allergen-specific $\operatorname{IgE}>0.35 \mathrm{kU} / \mathrm{L}$ for at least 1 of 6 allergens (Alternaria, birch, cat dander, dog dander, Dermatophagoides farina, Japanese hop). 
Table 2. Association of low and high MWP metabolites with Rrs5 and FeNO.

\begin{tabular}{|c|c|c|c|c|c|c|c|c|c|}
\hline \multirow[t]{2}{*}{$\begin{array}{l}\text { Quartiles } \\
\text { of uri- } \\
\text { nary } \\
\text { phthalate }\end{array}$} & Rrs5 & Rrs5 & Rrs5 & Rrs5 & Rrs5 & FeNO & FeNO & FeNO & FeNO \\
\hline & $\begin{array}{l}\text { Crude } \\
\beta \\
(95 \% \\
\text { CI })\end{array}$ & $\begin{array}{l}P \\
\text { value }\end{array}$ & & $\begin{array}{l}\text { Adjusted } \\
\beta \\
(95 \% \\
\text { CI })\end{array}$ & $\begin{array}{l}P \\
\text { value }\end{array}$ & $\begin{array}{l}\text { Crude } \\
\beta \\
(95 \% \\
\text { CI })\end{array}$ & $\begin{array}{l}P \\
\text { value }\end{array}$ & & $\begin{array}{l}\text { Adjusted } \\
\beta \\
(95 \% \\
\text { CI })\end{array}$ \\
\hline \multicolumn{10}{|l|}{$\begin{array}{l}\text { High } \\
\text { MWP }\end{array}$} \\
\hline Q1 & Ref & - & & Ref & - & Ref & - & & Ref \\
\hline Q2 & $\begin{array}{l}0.039 \\
(-0.015 \\
\text { to } \\
0.093)\end{array}$ & 0.160 & & $\begin{array}{l}0.017 \\
(-0.030 \\
\text { to } \\
0.063)\end{array}$ & 0.490 & $\begin{array}{l}-0.062 \\
(-0.215 \\
\text { to } \\
0.090)\end{array}$ & 0.425 & & $\begin{array}{l}-0.07 \\
(-0.153 \\
\text { to } \\
0.138)\end{array}$ \\
\hline Q3 & $\begin{array}{l}0.036 \\
(-0.018 \\
\text { to } \\
0.090)\end{array}$ & 0.195 & & $\begin{array}{l}0.017 \\
(-0.029 \\
\text { to } \\
0.064)\end{array}$ & 0.466 & $\begin{array}{l}-0.074 \\
(-0.226 \\
\text { to } \\
0.077)\end{array}$ & 0.334 & & $\begin{array}{l}-0.043 \\
(-0.188 \\
\text { to } \\
0.102)\end{array}$ \\
\hline Q4 & $\begin{array}{l}0.096 \\
(0.042 \\
\text { to } \\
0.150)\end{array}$ & 0.001 & & $\begin{array}{l}0.043 \\
(-0.004 \\
\text { to } \\
0.090)\end{array}$ & 0.076 & $\begin{array}{l}0.144 \\
(-0.008 \\
\text { to }-.295)\end{array}$ & 0.064 & & $\begin{array}{l}0.185 \\
(0.038 \\
\text { to } \\
0.332)\end{array}$ \\
\hline $\begin{array}{l}P \text { for } \\
\text { trend }\end{array}$ & $\begin{array}{l}0.028 \\
(0.011 \\
\text { to } \\
0.046)\end{array}$ & 0.001 & & $\begin{array}{l}0.013 \\
(-0.002 \\
\text { to } \\
0.028)\end{array}$ & 0.090 & $\begin{array}{l}0.042 \\
(-0.005 \\
\text { to } 0090)\end{array}$ & 0.077 & & $\begin{array}{l}0.053 \\
(0.007 \\
\text { to } \\
0.099)\end{array}$ \\
\hline $\begin{array}{l}\text { Low } \\
\text { MWP }\end{array}$ & & & & & & & & & \\
\hline Q1 & Ref & - & & Ref & - & Ref & - & & Ref \\
\hline Q2 & $\begin{array}{l}0.070 \\
(0.014 \\
\text { to } \\
0.124)\end{array}$ & 0.012 & & $\begin{array}{l}0.033 \\
(-0.014 \\
\text { to } \\
0.080)\end{array}$ & 0.167 & $\begin{array}{l}0.002 \\
(-0150 \\
\text { to } \\
0.154)\end{array}$ & 0.980 & & $\begin{array}{l}0.015 \\
(-0.133 \\
\text { to } \\
0.164)\end{array}$ \\
\hline Q3 & $\begin{array}{l}0.086 \\
(0.032 \\
\text { to } \\
0.140)\end{array}$ & 0.002 & & $\begin{array}{l}0.047 \\
(-0.000 \\
\text { to } \\
0.094)\end{array}$ & 0.050 & $\begin{array}{l}-0.124 \\
(-0.276 \\
\text { to } \\
0.028)\end{array}$ & 0.110 & & $\begin{array}{l}-0.108 \\
(-0.255 \\
\text { to } \\
0.039)\end{array}$ \\
\hline Q4 & $\begin{array}{l}0.088 \\
(0.034 \\
\text { to } \\
0.142)\end{array}$ & 0.001 & & $\begin{array}{l}0.061 \\
(0.014 \\
\text { to } \\
0.108)\end{array}$ & 0.011 & $\begin{array}{l}0.145 \\
(-0.006 \\
\text { to } \\
0.295)\end{array}$ & 0.059 & & $\begin{array}{l}0.137 \\
(-0.008 \\
\text { to } \\
0.283)\end{array}$ \\
\hline $\begin{array}{l}P \text { for } \\
\text { trend }\end{array}$ & $\begin{array}{l}0.028 \\
(0.011 \\
\text { to } \\
0.045)\end{array}$ & 0.001 & & $\begin{array}{l}0.020 \\
(0.005 \\
\text { to } \\
0.034)\end{array}$ & 0.010 & $\begin{array}{l}0.034 \\
(-0.013 \\
\text { to } \\
0.081)\end{array}$ & 0.158 & & $\begin{array}{l}0.032 \\
(-0.014 \\
\text { to } \\
0.077)\end{array}$ \\
\hline
\end{tabular}

MWP, molecular weight phthalate; Rrs5, resistance of respiratory system at $5 \mathrm{~Hz}$; FeNO, fractional nitric 
oxide; CI, confidence interval; Ref, reference

Rrs5 evaluations adjusted for height, gender, BMI $z$ score, secondary smoking, aeroallergen sensitization, and vitamin D level. FeNO evaluations adjusted for age, gender, BMI $z$ score, secondary smoking, aeroallergen sensitization, and vitamin D level. Pvalues are from a generalized linear regression with a gamma function.

Table 3. Association of serum periostin and YKL-40 levels with high and low MWP metabolites.

\begin{tabular}{|c|c|c|c|c|c|c|c|c|c|}
\hline $\begin{array}{l}\text { Quartiles } \\
\text { of uri- } \\
\text { nary } \\
\text { phthalate }\end{array}$ & $\begin{array}{l}\text { Periostin } \\
\text { (high } \\
\text { vs. } \\
\text { low) }\end{array}$ & $\begin{array}{l}\text { Periostin } \\
\text { (high } \\
\text { vs. } \\
\text { low) }\end{array}$ & $\begin{array}{l}\text { Periostin } \\
\text { (high } \\
\text { vs. } \\
\text { low) }\end{array}$ & $\begin{array}{l}\text { Periostin } \\
\text { (high } \\
\text { vs. } \\
\text { low) }\end{array}$ & $\begin{array}{l}\text { Periostin } \\
\text { (high } \\
\text { vs. } \\
\text { low) }\end{array}$ & $\begin{array}{l}\text { YKL- } \\
40 \\
\text { (high } \\
\text { vs. } \\
\text { low) }\end{array}$ & $\begin{array}{l}\text { YKL- } \\
40 \\
\text { (high } \\
\text { vs. } \\
\text { low) }\end{array}$ & $\begin{array}{l}\text { YKL- } \\
40 \\
\text { (high } \\
\text { vs. } \\
\text { low) }\end{array}$ & $\begin{array}{l}\text { YKL- } \\
40 \\
\text { (high } \\
\text { vs. } \\
\text { low) }\end{array}$ \\
\hline & $\begin{array}{l}\text { OR } \\
(95 \% \\
\mathrm{CI})\end{array}$ & $\begin{array}{l}P \\
\text { value }\end{array}$ & & $\begin{array}{l}\mathrm{aOR} \\
(95 \% \\
\mathrm{CI})\end{array}$ & $\begin{array}{l}P \\
\text { value }\end{array}$ & $\begin{array}{l}\text { OR } \\
(95 \% \\
\text { CI })\end{array}$ & $\begin{array}{l}P \\
\text { value }\end{array}$ & & $\begin{array}{l}\mathrm{aOR} \\
(95 \% \\
\mathrm{CI})\end{array}$ \\
\hline $\begin{array}{l}\text { High } \\
\text { MWP }\end{array}$ & & & & & & & & & \\
\hline Q1 & Ref & - & & Ref & - & Ref & - & & Ref \\
\hline Q2 & $\begin{array}{l}2.322 \\
(1.349 \\
\text { to } \\
3.998)\end{array}$ & 0.002 & & $\begin{array}{l}2.134 \\
(1.232 \\
\text { to } \\
3.696)\end{array}$ & 0.007 & $\begin{array}{l}0.926 \\
(0.543 \\
\text { to } \\
1.581)\end{array}$ & 0.778 & & $\begin{array}{l}1.055 \\
(0.604 \\
\text { to } \\
1.842)\end{array}$ \\
\hline Q3 & $\begin{array}{l}2.259 \\
(1.306 \\
\text { to } \\
3.906)\end{array}$ & 0.004 & & $\begin{array}{l}2.022 \\
(1.166 \\
\text { to } \\
3.508)\end{array}$ & 0.012 & $\begin{array}{l}0.617 \\
(0.360 \\
\text { to } \\
1.056)\end{array}$ & 0.078 & & $\begin{array}{l}0.593 \\
(0.339 \\
\text { to } \\
1.038)\end{array}$ \\
\hline $\mathrm{Q} 4$ & $\begin{array}{l}2.259 \\
(1.306 \\
\text { to } \\
3.906)\end{array}$ & 0.004 & & $\begin{array}{l}1.994 \\
(1.141 \\
\text { to } \\
3.484)\end{array}$ & 0.015 & $\begin{array}{l}0.655 \\
(0.380 \\
\text { to } \\
1.130)\end{array}$ & 0.128 & & $\begin{array}{l}0.634 \\
(0.360 \\
\text { to } \\
1.118)\end{array}$ \\
\hline $\begin{array}{l}P \text { for } \\
\text { trend }\end{array}$ & $\begin{array}{l}1.270 \\
(1.070 \\
\text { to } \\
1.507)\end{array}$ & 0.006 & & $\begin{array}{l}1.222 \\
(1.026 \\
\text { to } \\
1.455)\end{array}$ & 0.025 & $\begin{array}{l}0.845 \\
(0.711 \\
\text { to } \\
1.003)\end{array}$ & 0.054 & & $\begin{array}{l}0.882 \\
(0.687 \\
\text { to } \\
0.983)\end{array}$ \\
\hline $\begin{array}{l}\text { Low } \\
\text { MWP }\end{array}$ & & & & & & & & & \\
\hline Q1 & Ref & - & & Ref & - & Ref & - & & Ref \\
\hline Q2 & $\begin{array}{l}1.538 \\
(0.897 \\
\text { to } \\
2.639)\end{array}$ & 0.118 & & $\begin{array}{l}1.679 \\
(0.972 \\
\text { to } \\
2.899)\end{array}$ & 0.063 & $\begin{array}{l}1.505 \\
(0.880 \\
\text { to } \\
2.573)\end{array}$ & 0.135 & & $\begin{array}{l}1.468 \\
(0.838 \\
\text { to } \\
2.573)\end{array}$ \\
\hline Q3 & $\begin{array}{l}1.481 \\
(0.868 \\
\text { to } 2.528)\end{array}$ & 0.150 & & $\begin{array}{l}1.342 \\
(0.774 \\
\text { to } \\
2.329)\end{array}$ & 0.295 & $\begin{array}{l}1.056 \\
(0.619 \\
\text { to } \\
1.801)\end{array}$ & 0.843 & & $\begin{array}{l}0.929 \\
(0.530 \\
\text { to } \\
1.626)\end{array}$ \\
\hline Q4 & $\begin{array}{l}2.436 \\
(1.408 \\
\text { to } \\
4.216)\end{array}$ & 0.001 & & $\begin{array}{l}2.313 \\
(1.322 \\
\text { to } \\
4.048)\end{array}$ & 0.003 & $\begin{array}{l}1.050 \\
(0.612 \\
\text { to } \\
1.800)\end{array}$ & 0.843 & & $\begin{array}{l}0.891 \\
(0.508 \\
\text { to } \\
1.563)\end{array}$ \\
\hline
\end{tabular}




\begin{tabular}{llllllllll}
\hline & & & & & & YKL- & YKL- & YKL- & YKL- \\
Quartiles & Periostin & Periostin & Periostin & Periostin & Periostin & 40 & 40 & 40 & 40 \\
of uri- & (high & (high & (high & (high & (high & (high & (high & (high & (high \\
nary & vs. & vs. & vs. & vs. & vs. & vs. & vs. & vs. & vs. \\
phthalate & low) & low) & low) & low) & low) & low) & low) & low) & low) \\
\hline$P$ for & $\mathbf{1 . 2 9 9}$ & $\mathbf{0 . 0 0 3}$ & & $\mathbf{1 . 2 5 7}$ & $\mathbf{0 . 0 1 1}$ & 0.980 & 0.820 & & 0.924 \\
trend & $\mathbf{( 1 . 0 9 4}$ & & & $\mathbf{( 1 . 0 5 4}$ & & $(0.827$ & & $(0.773$ \\
& to & & & to & & to & & to \\
& $\mathbf{1 . 5 4 2 )}$ & & & $\mathbf{1 . 4 9 8}$ & & $1.162)$ & & $1.103)$ \\
\hline
\end{tabular}

YKL-40, chitinase-like proteins; MWP, molecular weight phthalate; OR, odds ratio; CI, confidence interval Periostin and YKL-40 (high vs. low) adjusted for age, gender, BMI $z$ score, aeroallergen sensitization, and secondary smoking. $P$ values are from a generalized linear regression with the logit function.

Table 4. Relationship of periostin and YKL-40 levels with lung function (Rrs5 and FeNO).

\begin{tabular}{|c|c|c|c|c|c|c|}
\hline & Rrs5 & Rrs5 & Rrs5 & Rrs5 & Rrs5 & $\mathrm{FeNO}$ \\
\hline & Crude $\beta(95 \%$ CI $)$ & $P$ value* & & Adjusted $\beta(95 \% \mathrm{CI})$ & $P$ value & Crude $\beta(95 \% \mathrm{CI})$ \\
\hline Periostin & & & & & & \\
\hline Low level & Ref & - & & Ref & - & Ref \\
\hline $\begin{array}{l}\text { High level } \\
\text { Chitinase }\end{array}$ & $0.053(0.013$ to 0.092$)$ & 0.008 & & $0.048(0.015$ to 0.081$)$ & 0.005 & $0.055(-0.057$ to 0.168$)$ \\
\hline Low level & Ref & - & & Ref & - & Ref \\
\hline High level & $0.024(-0.016$ to 0.064$)$ & 0.240 & & $0.007(-0.031$ to 0.045$)$ & 0.731 & $0.031(-0.082$ to 0.143$)$ \\
\hline
\end{tabular}

YKL-40, chitinase-like proteins; Rrs5, resistance of respiratory system at $5 \mathrm{~Hz}$; FeNO, fractional nitric oxide

*Adjusted for gender, height, BMI z score, aeroallergen sensitization, secondary smoking, and vitamin D level using a generalized linear regression with the gamma function.

Figure legends

Figure 1. Effect of frequency on impulse oscillometry resistance in children with different levels of $\Sigma_{4} \mathrm{HMWP}$ metabolites (A) and $\Sigma_{3}$ LMWP metabolites (B). Lines were determined by locally weighted smoothing functions and shaded areas indicate $95 \%$ confidence intervals. The level of $\Sigma_{4}$ HMWP metabolites (A) was significantly associated with Rrs1, Rrs2, and Rrs3 after adjusting for height, gender, BMI $z$ - score, aeroallergen sensitization, secondary smoking, and vitamin D level. The level of $\Sigma_{3}$ LMWP metabolites (B) was significantly associated with Rrs1, Rrs2, Rrs3, Rrs5, Rrs10, and Rrs15 after adjusting for these same factors. LMHP, low molecular weight phthalate; HMWP, high molecular weight phthalate; Rrs, respiratory system resistance.

Figure 2. Mediation model used to investigate the effect of serum periostin on the relationship between LMWP metabolites and lung dysfunction (Rrs5). The level of $\Sigma_{3}$ LMWP metabolites was significantly and directly associated with Rrs5 ( $\beta$ : $0.084,95 \%$ CI: 0.005 to $0.14, P=0.04$ ), and periostin ( $\beta$ : $0.013,95 \%$ CI: 0.002 to $0.030, P<0.001)$ mediated $13.8 \%$ of this effect (95\% CI: 10.7 to $77.0, P<0.001)$. The analysis adjusted for height, gender, BMI $z$ - score, aeroallergen sensitization, secondary smoking, and vitamin D level. LMWP, low molecular weight phthalate; Rrs5, respiratory system resistance at $5 \mathrm{~Hz}$.

Supplementary Figure E1. Concentrations ( $\mu \mathrm{g} / \mathrm{g}$ creatinine) of LMWP metabolites (top) and HMWP metabolites (bottom) in 487 urine samples. MEHHP, mono-(2-ethyl-5-hydroxyhexyl) phthalate; MCPP, 
mono-(3-carboxypropyl) phthalate; MECPP, mono-(2-ethyl-5-carboxypentyl) phthalate; MiBP, mono-(isobutyl) phthalate; MEOHP, mono-(2-ethyl-5-oxohexyl) phthalate; MNP, mono-isononyl phthalate; MBzP), mono-benzyl phthalate. Horizontal lines separate the different quartiles.

\section{Hosted file}

Phthalate Periostin Figure.pptx available at https://authorea.com/users/335900/articles/ 493170-association-of-phthalate-exposure-and-airway-dysfunction-with-mediation-by-serumperiostin 